METALLURGY AND FOUNDRY ENGINEERING - Vol. 35, 2009, No. 1

Janusz Krawczyk*, Bogdan Pawłowski*, Piotr Bała*

\title{
BANDED MICROSTRUCTURE IN FORGED 18CrNiMo7-6 STEEL
}

\section{INTRODUCTION}

18CrNiMo7-6 steel is applied for production of machine elements, which require hard surface layers and ductile cores, such as: toothed wheels, worms, shafts, sleeves of large dimensions subjected to high pressures and loads [1]. This steel is determined according to PN-EN 10084:2002 as alloy steel for carburizing. Forgings of this steel intended for toothed wheels are produced, among others.

Customers of forgings for toothed wheels are setting high requirements concerning non-metallic inclusions and micro-shrinkages as well as micro-cracks. Due to this, the acceptance of forgings is being made on the bases of ultrasonic tests. Occurrence of heterogeneous microstructures, visible banding (ferrite and pearlite bands), renders difficult the acceptance procedure. In addition an occurrence of banding can promote tooth breaking during toothed wheels exploitation.

Already in the fifties of the previous century the mechanisms of banding formation in steels was partially determined [2,3]. This phenomenon was explained by the influence of alloying elements segregation - taking place during an ingot crystallisation - on carbon activity in solid solutions and formation of zones of high and low carbon concentrations [2]. Another explanation was an influence of alloying elements on the $\mathrm{Ar}_{3}$ temperature [3]. Ferrite-stabilizing elements increasing locally the $\mathrm{Ar}_{3}$ temperature (in zones of an increased concentration of the given element caused by the segregation) will favour the transformation of austenite into ferrite earlier than in zones enriched in austenite-stabilizing elements [3].

The results of contemporary investigations $[4,5]$ confirm also that the primary reason of the ferrite-pearlite banded microstructure is heterogeneity of the chemical composition on the cross-section of a plastic worked semi-finished product. It is caused by the alloying

* Ph.D.: Faculty of Metals Engineering and Industrial Computer Science, AGH - University of Science and Technology, Kraków, Poland; e-mail: jkrawczy@metal.agh.edu.pl 
elements segregation during the steel crystallisation. The authors of the cited papers are of the opinion that a modification of the heat-plastic treatment parameters can significantly limit the banded microstructure formation. However, the heat treatment will not fully liquidate the primary reason, it means the segregation of elements. Further heat treatment operations can lead to the reoccurrence of a ferrite-pearlite banded microstructure.

The results of investigations of banded microstructure on the forging cross-section from 18CrNiMo7-6 steel in as-forged condition (after hot-forging) and after further heat treatment, are presented in the paper.

\section{MATERIAL AND INVESTIGATION METHOD}

Investigations were performed on materials taken from industrial forging made of 18CrNiMo7-6 steel (according to old PN. 17HNM, according to DIN - 1.6587) of the chemical composition shown in Table 1 .

Table 1. Chemical composition (mass \%) of the investigated $18 \mathrm{CrNiMo} 7-6$ steel

\begin{tabular}{|c|c|c|c|c|c|c|c|c|c|c|c||}
\hline $\mathrm{C}$ & $\mathrm{Si}$ & $\mathrm{Mn}$ & $\mathrm{P}$ & $\mathrm{S}$ & $\mathrm{Cr}$ & $\mathrm{Mo}$ & $\mathrm{Ni}$ & $\mathrm{Cu}$ & $\mathrm{Al}$ & $\mathrm{Ti}$ & $\mathrm{V}$ \\
\hline 0.16 & 0.24 & 0.43 & 0.008 & 0.005 & 1.55 & 0.26 & 1.44 & 0.20 & 0.033 & 0.01 & 0.01 \\
\hline
\end{tabular}

The requirements concerning the mass concentration of alloying elements for this steel - according to PN-EN 10084:2002 - are listed in Table 2.

Table 2. Chemical composition (mass \%) of 18CrNiMo7-6 steel, acc. PN-EN 10084:2002

\begin{tabular}{|c|c|c|c|c|c|c|c||}
\hline $\mathrm{C}$ & $\mathrm{Si}_{\max }$ & $\mathrm{Mn}$ & $\mathrm{P}_{\max }$ & $\mathrm{S}_{\max }$ & $\mathrm{Cr}$ & $\mathrm{Mo}$ & $\mathrm{Ni}$ \\
\hline $0.15 \div 0.21$ & 0.40 & $0.50 \div 0.90$ & 0.035 & 0.035 & $1.50 \div 1.80$ & $0.25 \div 0.35$ & $1.40 \div 1.70$ \\
\hline
\end{tabular}

As can be seen, the chemical composition of the investigated steel is within the range required by the standard, with an exception of manganese, the contents of which is below the range.

The samples, quenched in oil from an austenitizing temperature of $850^{\circ} \mathrm{C}$ were characterised by: $\mathrm{R}_{\mathrm{P} 0,2}=1146 \mathrm{MPa}, \mathrm{R}_{\mathrm{m}}=1261 \mathrm{MPa}, \mathrm{A}_{5}=11.6 \%, \mathrm{Z}=46.5 \%$, and impact strength $\mathrm{KCV}=64-67 \mathrm{~J} / \mathrm{cm}^{2}$. The producer determined also an apparent grain size of austenite as 8 MQE, acc. PN-04507.

Material for investigations was taken from the middle part of forging of a circular cross-section and a diameter of $335 \mathrm{~mm}$. Changes in microstructure and hardness on the cross-section of forging were analysed on the plane parallel to the forging axis and perpendicular to its surface. Tests were performed on samples in as-forged condition (after hot-forging) as well as on samples austenitized for 4 hours at a temperature of $850^{\circ} \mathrm{C}$, cooled to a temperature of $600^{\circ} \mathrm{C}$ with a cooling rate $3^{\circ} \mathrm{C} / \mathrm{min}$ (below the expected diffusive transformations range), and then cooled with a furnace. 
Hardness tests were made by means of the Vickers hardness tester, type HPO 250 at the penetrator load being $30 \mathrm{kG}$.

Metallographic observations were performed by the light microscope Axiover 200MAT of the CARL ZEISS Company. Polished sections were etched by $2 \%$ nital solution $\left(2 \% \mathrm{HNO}_{3}\right.$ in $\left.\mathrm{C}_{2} \mathrm{H}_{5} \mathrm{OH}\right)$.

\section{INVESTIGATION RESULTS AND THEIR DISCUSSION}

The hardness distribution on the cross-section of forging in as-delivered condition (after hot forging) are shown in Figure 1a. The influence of the applied heat treatment on a hardness at the cross-section of forging is presented in Figure $1 \mathrm{~b}$.
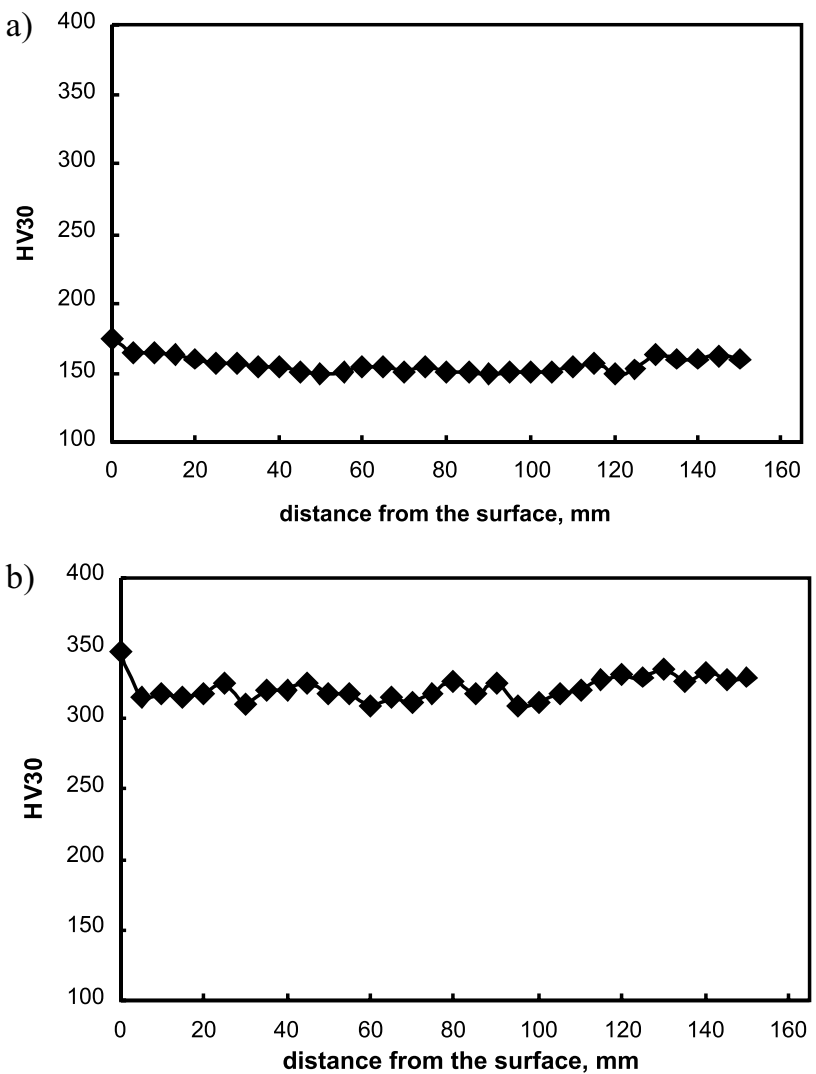

Fig. 1. Hardness distribution on the cross-section of forging made of 18CrNiMo7-6 steel: a) after hot-forging; b) after heat treatment

Microstructures, observed at distances increasing by $5 \mathrm{~mm}$ from the surface to the axis of the sample after forging and cooling with a furnace are presented in Figure 2 and 3 . Microstructures, in the same forged places, after the applied heat treatment are presented in Figure 4 and 5. 
a)

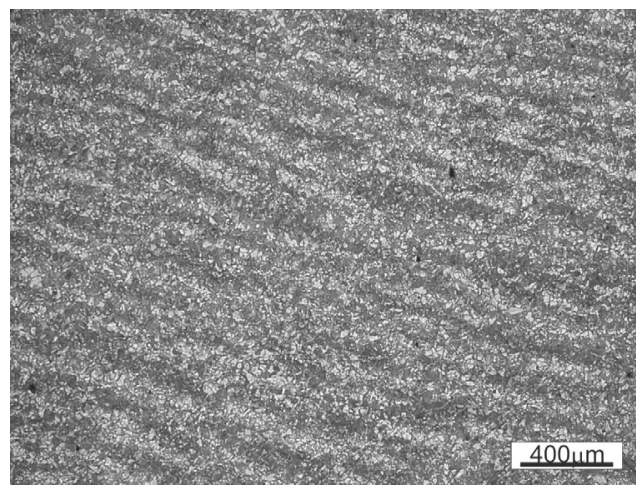

c)

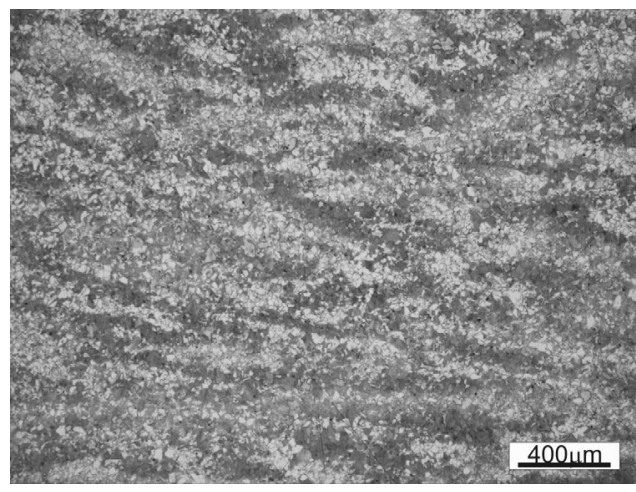

e)

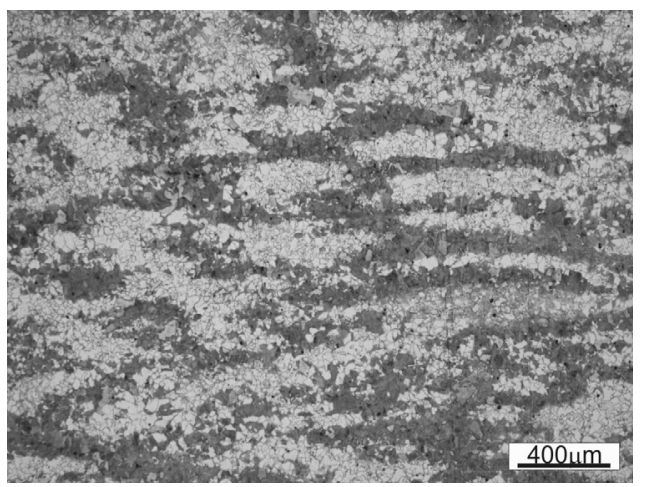

b)

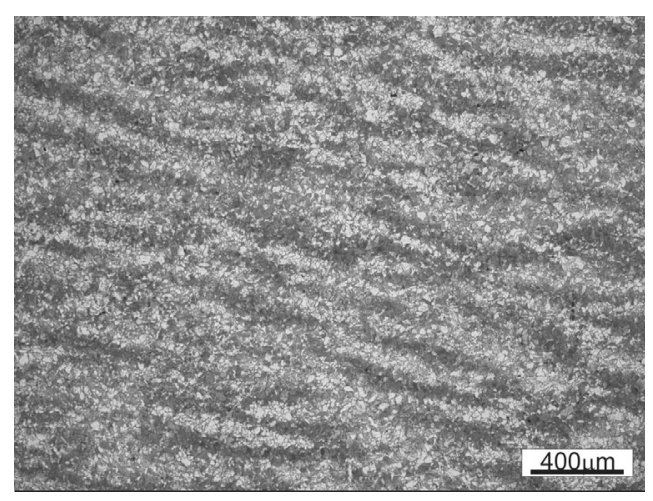

d)

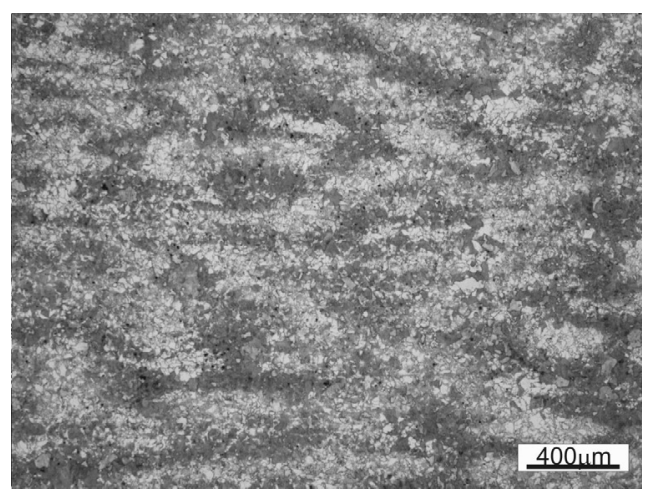

f)

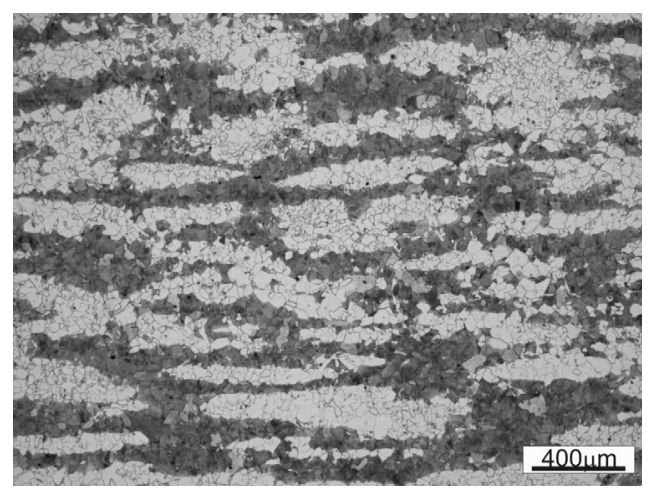

Fig. 2. Microstructure after forging. Distance from the surface: a) $5 \mathrm{~mm}$; b) $10 \mathrm{~mm}$; c) $20 \mathrm{~mm}$; d) $30 \mathrm{~mm}$; e) $40 \mathrm{~mm}$; f) $50 \mathrm{~mm}$. Etched with $2 \%$ nital 
a)

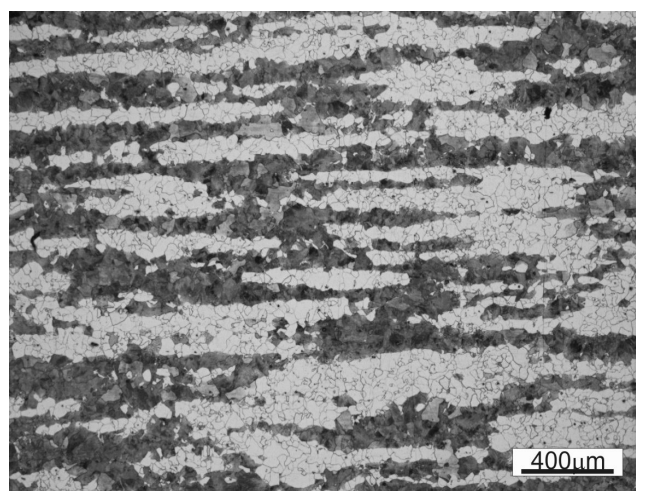

c)

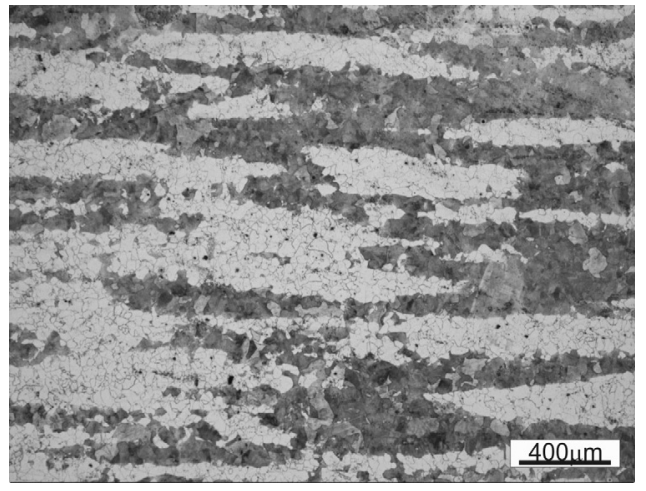

e)

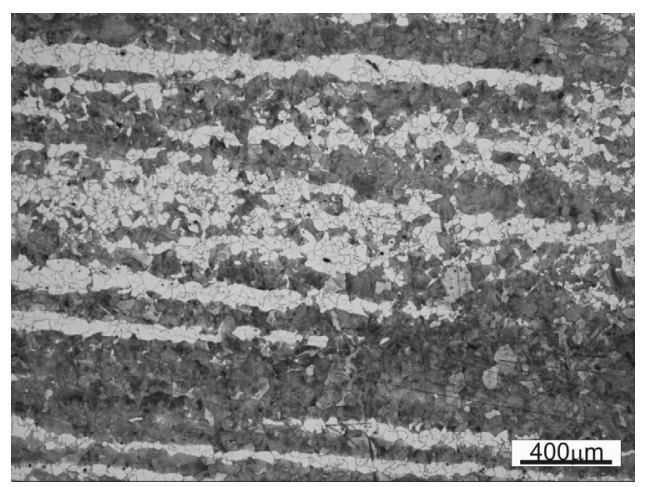

b)

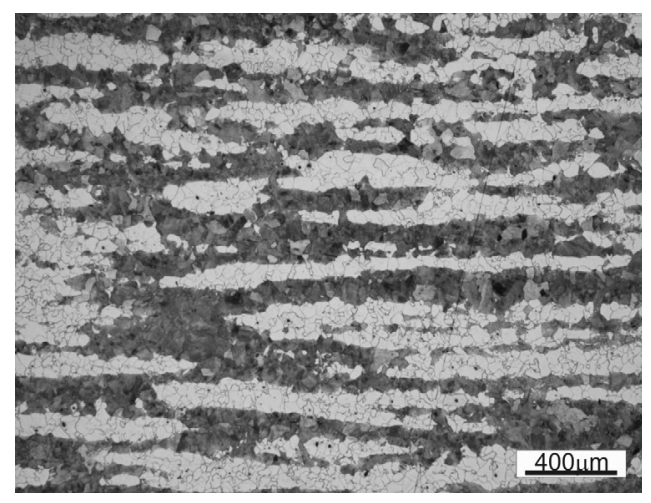

d)

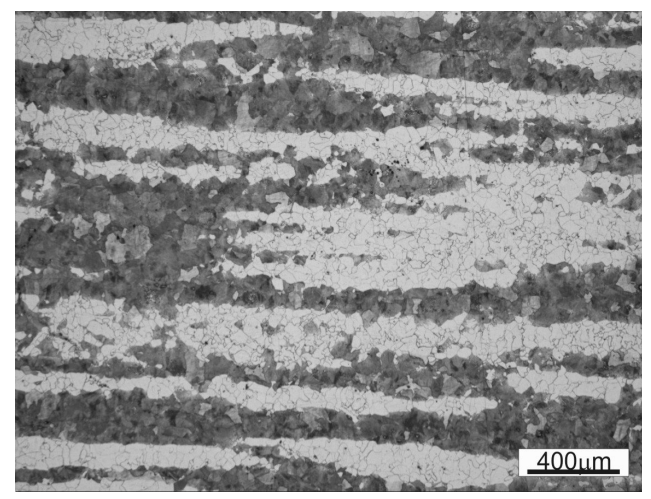

f)

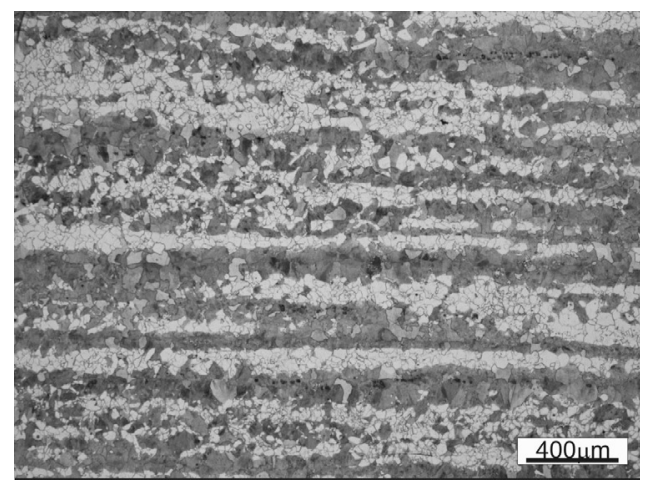

Fig. 3. Microstructure after forging. Distance from the surface: a) $60 \mathrm{~mm}$; b) $70 \mathrm{~mm}$; c) $85 \mathrm{~mm}$; d) $100 \mathrm{~mm}$; e) $130 \mathrm{~mm}$; f) $160 \mathrm{~mm}$. Etched with $2 \%$ nital 
a)

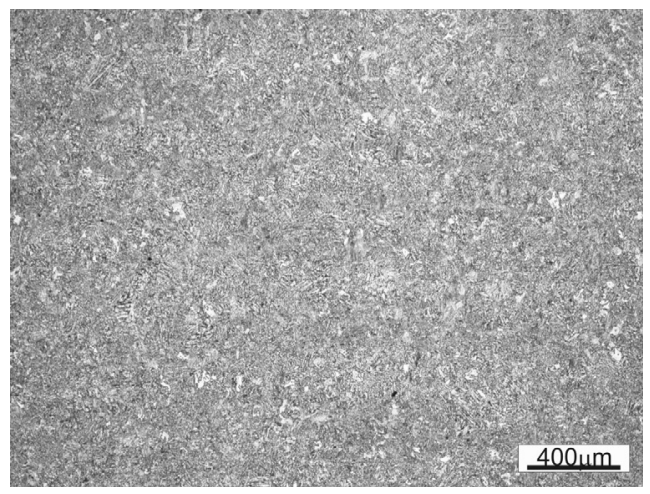

c)

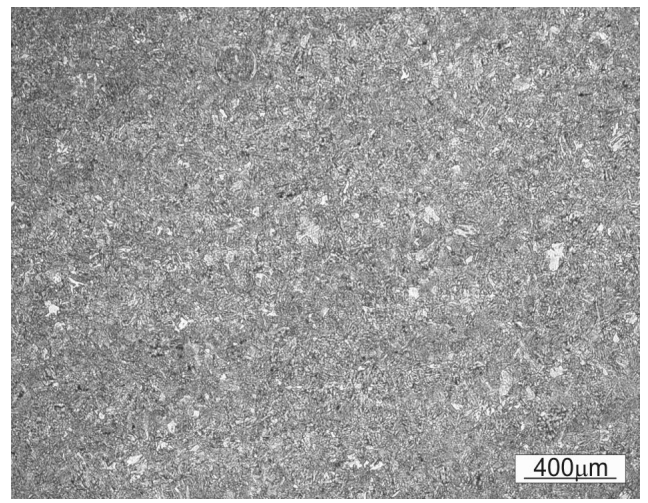

e)

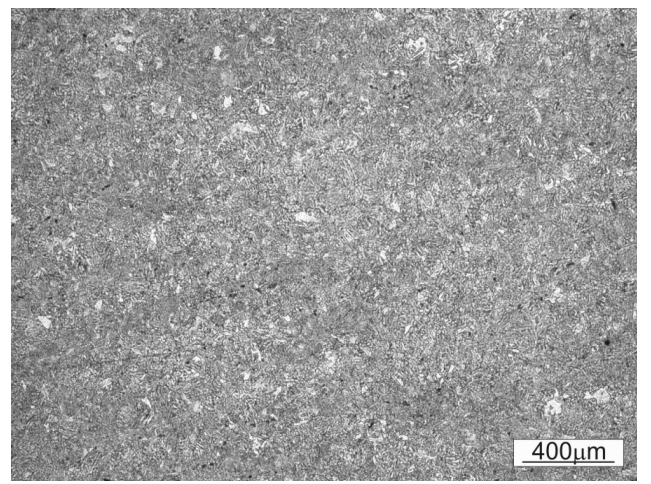

b)

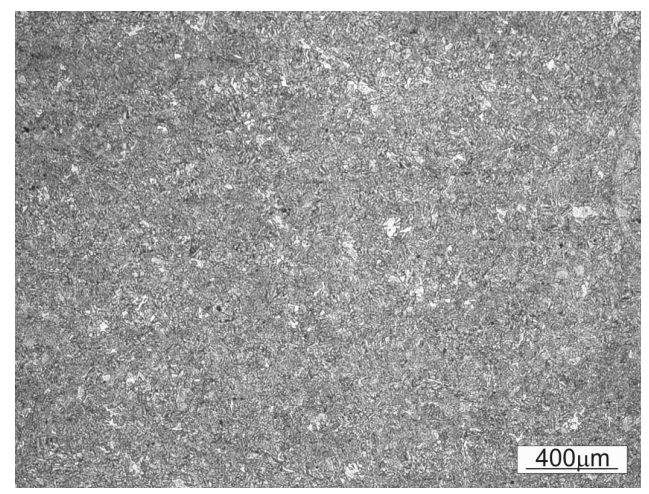

d)

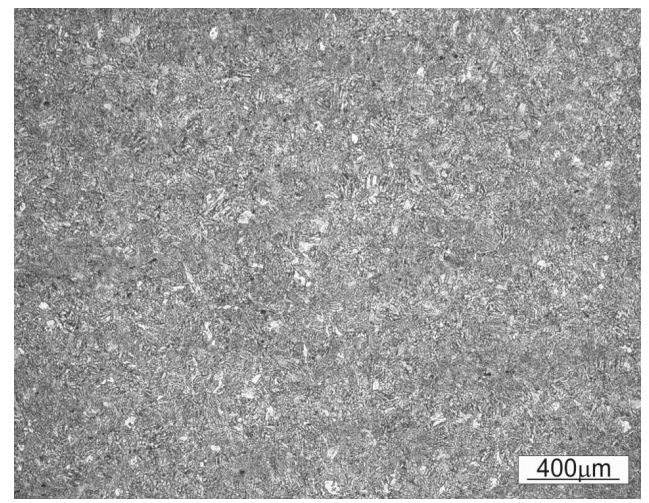

f)

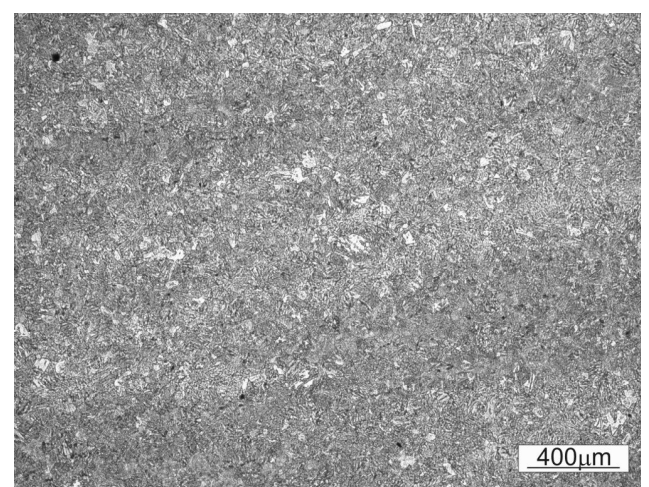

Fig. 4. Microstructure on the cross-section of the forging, after heat treatment. Distance from the surface: a) $5 \mathrm{~mm}$; b) $10 \mathrm{~mm}$; c) $20 \mathrm{~mm}$; d) $30 \mathrm{~mm}$; e) $40 \mathrm{~mm}$; f) $50 \mathrm{~mm}$. Etched with $2 \%$ nital 
a)

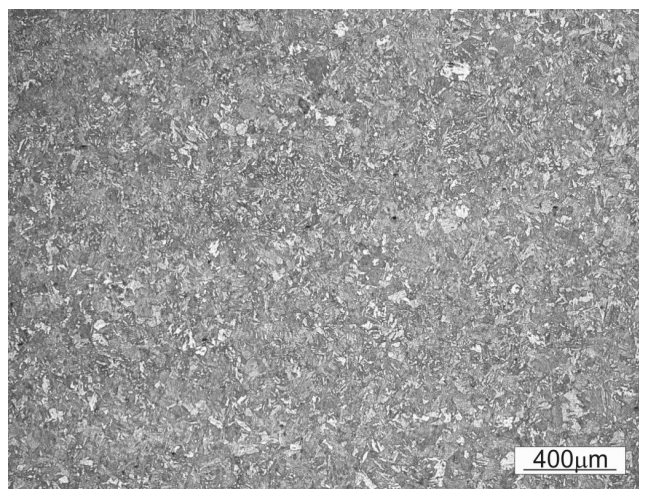

c)

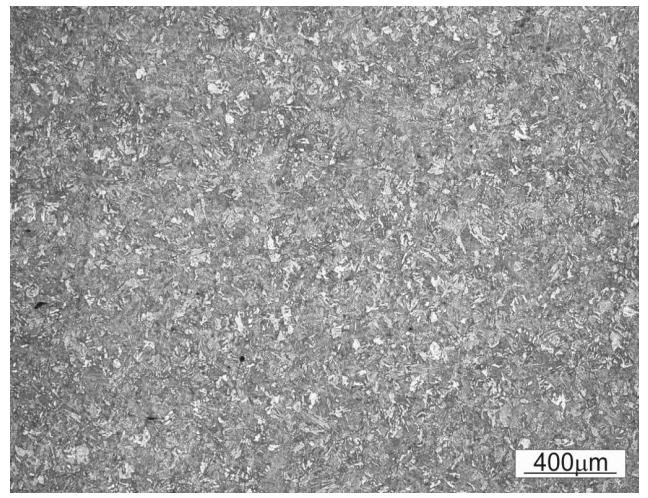

e)

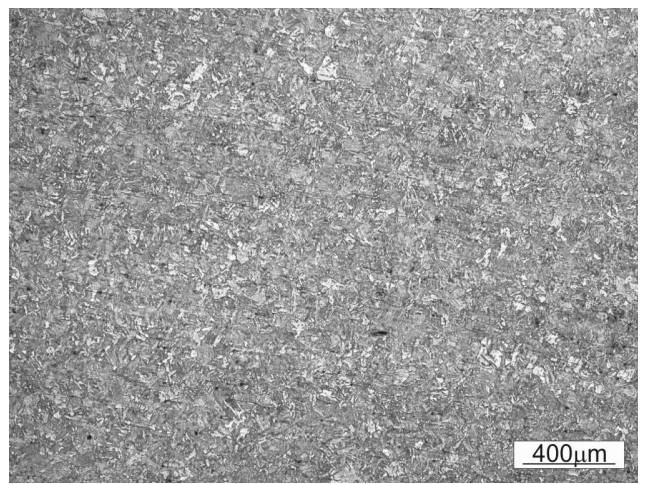

b)

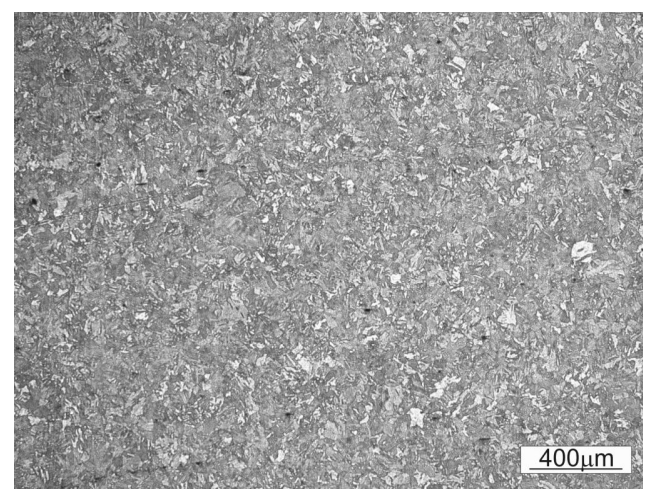

d)

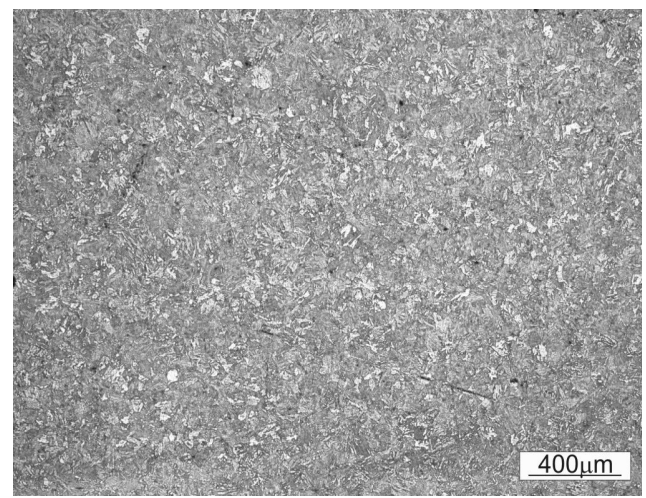

f)

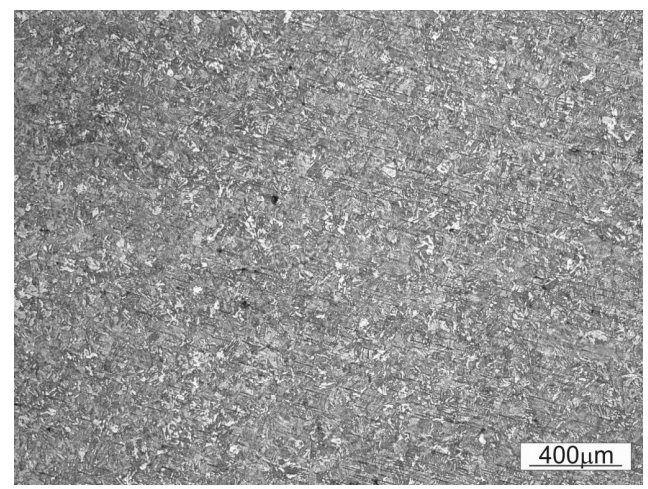

Fig. 5. Microstructure on the cross-section of the forging, after heat treatment. Distance from the surface a) $60 \mathrm{~mm}$; b) $70 \mathrm{~mm}$; c) $80 \mathrm{~mm}$; d) $100 \mathrm{~mm}$; e) $130 \mathrm{~mm}$; f) $145 \mathrm{~mm}$. Etched with $2 \%$ nital 
Observations of microstructure on the cross-section of the forging indicate significant differences in ferrite grain sizes, plate thickness in pearlitic microstructure, pearlite colony sizes and in banding. Generally ferrite grain sizes increase with an increasing distance from the surface. The significant increase of this grain size occurs $50 \mathrm{~mm}$ from the surface of forging. At the same depth the largest change of pearlite plates occurs. The closer to the surface these plates are finer while the closer to the core they are coarser. The place at a distance of $50 \mathrm{~mm}$ from the forging surface is also characteristic for a distinct size change of the pearlitic colony. The closer to the grain core the pearlite colonies are larger. In the case of banding phenomena more characteristic places can be found on the cross-section. When the distance from the surface increases the banding becomes more and more visible. In the near-surface layer to the depth of app. $15 \mathrm{~mm}$ (especially in the direct near-surface layer some $5 \mathrm{~mm}$ below it), bands are not parallel to the forging axis but inclined app. $35^{\circ}$ to the surface. This indicates an influence of a crystal structure on a forging banding. The microstructure at a depth of $40 \mathrm{~mm}$ from the surface - is characterised by a distinct banding in the direction parallel to the forging axis. Formation of pearlitic microstructures is initiated at the interface boundary of a growing ferrite grain as a result of an increased carbon concentration in austenitic matrix followed by a cementite nucleation on a shifting ferrite grain boundary. An analysis of hardness changes on the forging cross-section also indicates the effect of strengthening caused by grain refinement due to strong austenite deformation in the forging surface layer. This effect is the strongest in the near-surface layer (to $5 \mathrm{~mm}$ below the surface) and reaches down to $50 \mathrm{~mm}$ below the surface (gradual hardness decrease). It can be also related to the primary boundary in between the zones of frozen and columnar crystals being formed during the crystallisation process.

Hardness increases in the middle part (in the zone close to forging axis). This may be due to the segregation of alloying elements (especially chromium) into liquid during an ingot crystallisation. This segregation can also explain the local hardness increase at the depth of app. $25 \mathrm{~mm}$ (pushing out alloying elements in front of the crystallisation of columnar crystals). Forming of columnar crystals in the ingot surface layer can be also the reason of an occurrence of bands inclined at app. $35^{\circ}$ to the surface in the near-surface layer of the forging. Those bands can be a residue of columnar structures. Strong banding in the vicinity of the forging axis is probably the result of crystallisation followed by an equiaxial crystal growth as well as an uneven distribution of alloying additions and phosphor in between equiaxial crystals and liquid, in which they were growing.

In order to estimate the influence of compliance of microstructure occurring on the forging cross-section on its changes caused by the heat treatment the samples taken from the forging were annealed for 24 hours at a temperature of $850^{\circ} \mathrm{C}$ and then air cooled. Air cooling of samples was supposed to ensure obtaining the bainitic microstructure, which exhibits smaller inclination to banding.

As it can be seen in Figures 4 and 5 the applied heat treatment allowed to obtain bainitic microstructure, being independent of the cross-section place, from which the samples were taken. The microstructure presented in Figures 4 and 5 is characterised by quite clearly seen primary austenite grain boundaries and very small banding effects. A distinct hardness in- 
crease occurs only in the zone being near the forging surface (Fig. 1b). However, a small hardness increase can be seen in places being nearer to the forging axis and this can be explained by differences in the chemical composition on the cross-section.

\section{CONCLUSIONS}

The following conclusions can be formulated on the basis of the performed investigations:

1. Strong banding of the ferritic-pearlitic microstructure occurs in the forging of $18 \mathrm{CrNiMo} 7-6$ steel in as-hot-forged condition. This is the most probably related to the alloying elements segregation during the ingot crystallisation process.

2. The applied heat treatment allowed to obtain the bainitic microstructure.

3. The bainitic microstructure on the forging cross-section, after the heat treatment, exhibits very weak banded traces.

\section{REFERENCES}

[1] Dobrzański L.A.: Engineering materials and materials design, Fundamentals of materials science and physical metallurgy. WNT, Warsaw-Gliwice, 2006 (in Polish)

[2] Bastien P.G.: The mechanism of formation of banded structures, Journal of Iron and Steel Institute, 187 (1957) 281-291

[3] Jatczak C.F., Girardi D.J., Rowland E.S.: On banding in steel, Transactions of the ASM. 48 (1956) 279-305

[4] Marcisz J., Garbarz B., Żak A.: Causes of banded microstructure formation in hot rolled ferrite-pearlite steel products, Metallurgy and Metallurgical Engineering News, 74 (2007) 12, 655-663 (in Polish)

[5] Marcisz J., Żak A., Garbarz B.: Methods for improving of homogeneity and plasticity of continuously cast steel semiproducts and products hot rolled or forged with small degree of reduction ratio, Transactions of the Institute for Ferrous Metallurgy, (2007) 1, 51-53 (in Polish)

Received

December 2009 